\title{
Hypernatremia at admission predicts poor survival in patients with terminal cancer: a retrospective cohort study
}

\author{
Min-Seok Seo ${ }^{1,2}$, In Cheol Hwang ${ }^{3^{*+}} \mathbb{D}$, Jaehun Jung ${ }^{4^{*}+}$, Hwanhee Lee ${ }^{3}$, Jae Hee Choi ${ }^{3}$ and Jae-Yong Shim ${ }^{2}$
}

\begin{abstract}
Background: Although palliative care providers, patients, and their families rely heavily on accurate prognostication, the prognostic value of electrolyte imbalance has received little attention.

Methods: As a retrospective review, we screened inpatients with terminal cancer admitted between January 2017 and May 2019 to a single hospice-palliative care unit. Clinical characteristics and laboratory results were obtained from medical records for multivariable Cox regression analysis of independent prognostic factors.

Results: Of the 487 patients who qualified, 15 (3\%) were hypernatremic upon admission. The median survival time was 26 days. Parameters associated with shortened survival included male sex, advanced age ( $>70$ years), lung cancer, poor performance status, elevated inflammatory markers, azotemia, impaired liver function, and hypernatremia. In a multivariable Cox proportional hazards model, male sex (hazard ratio $[H R]=1.53,95 \%$ confidence interval [Cl]: 1.15-2.04), poor performance status ( $H R=1.45,95 \% \mathrm{Cl}: 1.09-1.94)$, leukocytosis ( $H R=1.98$, 95\% Cl: 1.47-2.66), hypoalbuminemia ( $\mathrm{HR}=2.06,95 \% \mathrm{Cl}: 1.49-2.73)$, and hypernatremia ( $\mathrm{HR}=1.55,95 \% \mathrm{Cl}: 1.18-$ 2.03) emerged as significant predictors of poor prognosis.
\end{abstract}

Conclusion: Hypernatremia may be a useful gauge of prognosis in patients with terminal cancer. Further largescale prospective studies are needed to corroborate this finding.

Keywords: Electrolyte imbalance, Hypernatremia, Prognosis, Terminal cancer

\section{Background}

Accurately predicting the prognosis of patients with terminal cancer is helpful to guide clinical decisions and develop palliative care management plans. Over the past few decades, a number of studies have been conducted in this setting to identify patient-related prognostic factors, including performance status, anorexia-cachexia,

\footnotetext{
*Correspondence: spfe0211@gmail.com; eastside1st@gachon.ac.kr

${ }^{\dagger}$ In Cheol Hwang and Jaehun Jung contributed equally to this work.

${ }^{3}$ Department of Family Medicine, Gil Medical Center, Gachon University College of Medicine, 1198 Guwol-dong, Namdong-gu, Incheon 405-760, Republic of Korea

${ }^{4}$ Artificial Intelligence and Bigdata Convergence Center, Gachon University College of Medicine, Guwol-dong, Namdong-gu, Incheon 405-760, Republic of Korea

Full list of author information is available at the end of the article
}

delirium, and dyspnea [1]; and various laboratory abnormalities have similarly been identified. Serum markers of systemic inflammation (i.e., leukocytosis, lymphopenia, C-reactive protein [CRP] elevation, and inflammatory cytokines) are well-known indices of poor survival [2]. Biomarkers of hepatic dysfunction (elevated lactate dehydrogenase $[\mathrm{LDH}]$, prolonged international normalized ratio [INR], hypoalbuminemia) and renal impairment (serum urea, creatinine, and uric acid elevations) have also been implicated $[2,3]$.

Electrolyte abnormalities are common among terminal cancer patients and represent yet another significant means of predicting survival [4]. In an earlier study, 79\% of such patients showed at least one electrolyte

(c) The Author(s). 2020 Open Access This article is licensed under a Creative Commons Attribution 4.0 International License, which permits use, sharing, adaptation, distribution and reproduction in any medium or format, as long as you give appropriate credit to the original author(s) and the source, provide a link to the Creative Commons licence, and indicate if changes were made. The images or other third party material in this article are included in the article's Creative Commons licence, unless indicated otherwise in a credit line to the material. If material is not included in the article's Creative Commons licence and your intended use is not permitted by statutory regulation or exceeds the permitted use, you will need to obtain permission directly from the copyright holder. To view a copy of this licence, visit http://creativecommons.org/licenses/by/4.0/. The Creative Commons Public Domain Dedication waiver (http://creativecommons.org/publicdomain/zero/1.0/) applies to the data made available in this article, unless otherwise stated in a credit line to the data. 
abnormality upon referral for palliative care [5]. Hyponatremia is the most frequent electrolyte disorder of patients with terminal cancer, having dire consequences [6]. Its early detection and proper correction may actually prolong median survival time [7]. In cancer patients, hypernatremia caused by various etiologies such as excessive gain of sodium due to inadequate fluid replacement, excessive loss of free water, the use of osmotic agents, decreased release of antidiuretic hormone (ADH) and renal dysfunction to ADH [8]. Although hypernatremia is otherwise rare in these patients, offering little opportunity for study, there is evidence that the prognostic ramifications are negative due to a failure of feedback to compensate the imbalance $[9,10]$. Potassium imbalance is also a highly prevalent electrolyte disorder. In cancer patients, hypokalemia often presents in conjunction with hyponatremia and hypomagnesemia [4]. Previous studies suggested that hyperkalemia is a prognostically unfavorable determinant, but this view remains controversial $[11,12]$. Research on the prognostic utility of other electrolyte disorders including hypercalcemia and hypermagnesemia, has also been inconclusive $[5,13]$.

The present study was undertaken to assess the prevalence of electrolyte imbalance in terminally ill cancer patients and, investigate the potential prognostic significance.

\section{Methods}

This retrospective study reviewed medical records of 515 patients admitted to the palliative care unit of Incheon regional cancer center between January 2017 and May 2019. All participants were terminally ill with cancer and were not expected to survive beyond 6 months based on the clinical assessment of a medical oncologist and surgeon [14]. Ultimately, 10 patients who lacked serum electrolyte data and 18 patients transferred from other medical institutions were excluded, leaving 487 patients eligible for the final analysis. Patients who had no survival information available due to discharge to home or other institutions were also censored $(n=19)$. The institutional review board of Gachon University Gil Medical Center approved this study (GCIRB2019-149), waiving the need for informed patient consent as designed.

Electronic medical records provided the following patient data: age, sex, primary cancer site, Eastern Cooperative Oncology Group Performance Status (ECOGPS), evidence of active infection, survival times, and laboratory diagnostic results. The ECOG-PS is a scale $(0-4)$ used to assess physical ability. On day of admission, an experienced member of the palliative care team (physicians and registered nurses) scored each patient's functionality. Survival time was defined as the period from admission-day blood testing (electrolytes included) until the day of death. Laboratory testing on day of admission included total white blood cell (WBC) count with differential, hemoglobin, platelet count, serum creatinine, serum albumin, total bilirubin, INR, CRP, serum sodium, and potassium. Active infection was determined based on the use of antibiotics.

Descriptive data are expressed as medians and numbers of subjects. The Kaplan-Meier method and log-rank tests were invoked to measure differences in survival times across all patient characteristics, using Cox proportional hazards models to identify independent predictors of survival in univariable and multivariable analyses. Variables showing significance $(P<0.05)$ in univariable analysis were used in the final multivariable analysis. A two-tailed $P<0.05$ was deemed significant. All computations were performed using standard software (Stata SE v9.2; StataCorp, College Station, TX, USA).

\section{Results}

A total of 487 patients (men: 268, 55\%; women: $219,45 \%$ ) with terminal cancer qualified for study participation. Baseline clinical characteristics of the study population are shown in Table 1. Median age was 70 years. The most common type of malignancy was cancer of the gastrointestinal tract (127 patients, 26.1\%), followed by hepatopancreatobiliary cancer (118 patients, 24.2\%). ECOG-PS scores of 3 and 4 were recorded in 38.8 and $37.6 \%$ of patients, respectively. The median values of abnormal laboratory parameters were as follows: hemoglobin $10.1 \mathrm{~g} / \mathrm{dL}, \mathrm{CRP} 5.2 \mathrm{mg} / \mathrm{dL}$, and sodium $134 \mathrm{mEq} / \mathrm{L}$. The median survival time overall was 26 days.

Table 2 shows the survival time according to participant characteristics. Advanced age ( $>70$ years), male sex, lung cancer, poor performance status, leukocytosis, neutrophilia, lymphopenia, thrombocytopenia, azotemia, hypoalbuminemia, hyperbilirubinemia, prolonged prothrombin time (PT)-INR, elevated CRP, and hypernatremia were associated with significantly shorter median survival time.

Kaplan-Meier survival curves plotted by serum sodium level are depicted in Fig. 1. Hypernatremia patients survived shorter than those with eunatremia or hyponatremia $(P<0.001)$, whereas the difference in survival time between eunatremic and hyponatremic patients was not significant.

Table 3 presents independent prognostic factors identified from the Cox proportional hazards models. Multivariable analysis revealed that various parameters including male sex $(\mathrm{HR}=1.53 ; P=0.004)$, poor ECOGPS $(\mathrm{HR}=1.45, P=0.011)$, leukocytosis $(\mathrm{HR}=1.98, P<$ $0.001)$, hypoalbuminemia $(\mathrm{HR}=2.06, P<0.001)$, and hypernatremia $(\mathrm{HR}=1.55, P=0.002)$, were significantly associated with poor survival. 
Table 1 Characteristics of study participants $(N=487)$

\begin{tabular}{|c|c|c|}
\hline & Median (IQR) or n (\%) & Reference range \\
\hline Age, yrs & $70(59-79)$ & \\
\hline Female sex & $219(45.0)$ & \\
\hline \multicolumn{3}{|l|}{ Cancer site } \\
\hline Gastrointestinal tract & $127(26.1)$ & \\
\hline Hepatobiliary/pancreatic & $118(24.2)$ & \\
\hline Lung & $108(22.2)$ & \\
\hline Urogenital tract & $57(11.7)$ & \\
\hline Others & $77(15.8)$ & \\
\hline \multicolumn{3}{|l|}{ ECOG-PS } \\
\hline$\leq 2$ & $115(23.6)$ & \\
\hline 3 & $189(38.8)$ & \\
\hline 4 & $183(37.6)$ & \\
\hline Active infection ${ }^{a}$ & $164(33.7)$ & \\
\hline \multicolumn{3}{|l|}{ Laboratory parameter } \\
\hline White blood cells, $10^{3} / \mathrm{mm}^{3}$ & $9.1(6.3-12.7)$ & $3.8-10$ \\
\hline Neutrophils, \% & $78.9(72.0-85.7)$ & $50-75$ \\
\hline Lymphocytes, \% & $11.2(6.8-17.4)$ & $20-44$ \\
\hline Hemoglobin, g/dL & $10.1(8.8-11.7)$ & $13-17$ \\
\hline Platelets, $10^{3} / \mathrm{mm}^{3}$ & $227(154-323)$ & $150-400$ \\
\hline Creatinine, mg/dL & $0.8(0.5-1.2)$ & $0.5-1.2$ \\
\hline Albumin, g/dL & $3.2(2.8-3.7)$ & $3.5-5.2$ \\
\hline Total bilirubin, mg/dL & $0.7(0.5-1.4)$ & $0.2-1.2$ \\
\hline PT/INR & $1.2(1.1-1.3)$ & $0.8-1.2$ \\
\hline C-reactive protein, mg/dL & $5.2(2.3-12.9)$ & $0-0.5$ \\
\hline Sodium, mEq/L & $134(130-137)$ & $135-145$ \\
\hline Potassium, mEq/L & $4.2(3.8-4.6)$ & $3.5-5.5$ \\
\hline Censored $^{\mathrm{b}}$ & $19(3.9)$ & \\
\hline Survival time, days & $26(14-45)$ & \\
\hline
\end{tabular}

ECOG-PS Eastern Cooperative Oncology Group performance status, IQR interquartile range, $P T / I N R$ prothrombin time/international normalized ratio a Determined by the use of antibiotics

${ }^{b}$ No available information for survival by discharge or transfer

\section{Discussion}

The findings of the present study indicate that the prognosis is demonstrably poor for terminally ill cancer patients with hypernatremia (vs. eunatremia or hyponatremia). These results are in accordance with outcomes of previous studies, offering added support. Based on a group of 259 cancer patients referred for palliative care, Alsirafy et al. reported shorter median survival (8 days) and higher mortality (68\%) in those with hypernatremia than in hyponatremic or eunatremic patients [10]. However, multivariable analysis of well-known prognostic factors in terminal cancer patients had not been carried out. Our data demonstrate that the association between hypernatremia and poor survival remains robust after controlling for other predictors of survival.
Salahudeen et al. reported poor clinical outcomes involving higher mortality, longer hospitalization, and greater hospital expense in patients with hypernatremia [9]. There were some differences from our cohort of terminal patients whose life expectancies were approximately 6 months. They examined subjects admitted to a comprehensive cancer center with any stage of disease; and their focus was on iatrogenic hypernatremia since baseline hypernatremia contributed so few patients. In our investigation, laboratory testing took place on the day of admission, aimed at existing rather than acquired hypernatremia. Hence, this may be the first effort to explore the prognostic utility of spontaneous hypernatremia in terminally ill cancer patients.

The prevalence of hypernatremia in patients with terminal cancer is unclear. Salahudeen and colleagues found that hypernatremia in cancer patients increased from $0.2 \%$ on admission to $2.6 \%$ during the course of hospitalization [9]. Another study reported that $8.5 \%$ of adult cancer patients referred for palliative care are hypernatremic [10]. Similar to prior studies, we recorded a $3 \%$ prevalence of hypernatremia.

Little is known about the specific mechanism by which hypernatremia worsens survival, but there is at least one plausible explanation. Hypernatremia is generally induced by the loss of electrolyte-free water. Physiologic feedback mechanisms, such as thirst and ADH release, are then promptly activated to increase water intake and minimize additional free water loss. In a healthy population, elevated serum sodium levels return to the normal range [12]. However, feedback dysfunction in patients with terminal cancer may impede or prevent normalization of serum sodium concentrations, and many are faced with non-replenishment of water lost through excessive sweating, vomiting, diarrhea, and nasogastric drainage [15]. Impaired response to thirst due to diminished mental faculties or poor oral intake and subsequent dehydration may induce hypernatremia in such patients outside hospital environments. Still, there is virtually no research on hypernatremia in cancer patients. Retrospective studies of older adult patients and critically ill patients admitted to intensive care units would be helpful to understand this problem in the context of terminal cancer $[16,17]$. Mental debilitation and poor oral intake create rapid declines in their general conditions [18]. Although causality between hypernatremia and deteriorating general conditions remain in question, hypernatremic patients are extremely ill and less inclined to survive.

Certain prognostic factors-namely poor functional status, leukocytosis, and hypoalbuminemia-are well documented in past reports, but the data on effects of hyponatremia have been inconsistent. Several earlier endeavors have shown the negative prognostic aspect of 
Table 2 Survival time in relation to patient characteristics

\begin{tabular}{|c|c|c|c|}
\hline & $n$ & $\begin{array}{l}\text { Median survival, } \\
\text { days ( } 95 \% \mathrm{Cl})\end{array}$ & $P^{b}$ \\
\hline \multicolumn{4}{|l|}{ Age, years } \\
\hline$<70$ & 232 & $29(13-52)$ & \multirow[t]{2}{*}{0.003} \\
\hline$\geq 70$ & 255 & $24(14-40)$ & \\
\hline \multicolumn{4}{|l|}{ Sex } \\
\hline Female & 219 & $29(13-48)$ & \multirow[t]{2}{*}{0.035} \\
\hline Male & 268 & $24(14-40)$ & \\
\hline \multicolumn{4}{|l|}{ Cancer site } \\
\hline Gastrointestinal tract & 127 & $29(14-47)$ & \multirow[t]{5}{*}{0.012} \\
\hline Hepatobiliary/pancreatic & 118 & $24(13-33)$ & \\
\hline Lung & 108 & $22(12-41)$ & \\
\hline Urogenital tract & 57 & $27(13-55)$ & \\
\hline Others & 77 & $35(19-47)$ & \\
\hline \multicolumn{4}{|l|}{ ECOG-PS } \\
\hline$\leq 2$ & 115 & $30(18-50)$ & \multirow[t]{3}{*}{0.012} \\
\hline 3 & 189 & $27(14-48)$ & \\
\hline 4 & 183 & $23(11-40)$ & \\
\hline \multicolumn{4}{|l|}{ Active infection } \\
\hline No & 322 & $27(12-46)$ & \multirow[t]{2}{*}{0.558} \\
\hline Yes & 164 & $25(14-38)$ & \\
\hline \multicolumn{4}{|l|}{ Leukocytosis } \\
\hline No & 279 & $31(15-52)$ & \multirow[t]{2}{*}{$<0.001$} \\
\hline Yes & 208 & $22(11-34)$ & \\
\hline \multicolumn{4}{|l|}{ Neutrophilia } \\
\hline No & 173 & $31(18-55)$ & \multirow[t]{2}{*}{$<0.001$} \\
\hline Yes & 314 & $24(12-39)$ & \\
\hline \multicolumn{4}{|l|}{ Lymphopenia } \\
\hline No & 90 & $36(19-60)$ & \multirow[t]{2}{*}{$<0.001$} \\
\hline Yes & 397 & $25(13-41)$ & \\
\hline \multicolumn{4}{|l|}{ Anemia } \\
\hline No & 56 & $25(13-45)$ & \multirow[t]{2}{*}{0.707} \\
\hline Yes & 431 & $26(14-45)$ & \\
\hline \multicolumn{4}{|l|}{ Thrombocytopenia } \\
\hline No & 371 & $28(14-47)$ & \multirow[t]{2}{*}{0.020} \\
\hline Yes & 116 & $20(11-36)$ & \\
\hline \multicolumn{4}{|l|}{ Azotemia } \\
\hline No & 367 & $28(14-46)$ & \multirow[t]{2}{*}{0.011} \\
\hline Yes & 120 & $20(12-38)$ & \\
\hline \multicolumn{4}{|l|}{ Hypoalbuminemia } \\
\hline No & 176 & $35(20-60)$ & \multirow[t]{2}{*}{$<0.001$} \\
\hline Yes & 311 & $20(11-37)$ & \\
\hline \multicolumn{4}{|l|}{ Hyperbilirubinemia } \\
\hline No & 341 & $29(15-48)$ & $<0.001$ \\
\hline Yes & 145 & $19(10-32)$ & \\
\hline
\end{tabular}

Table 2 Survival time in relation to patient characteristics (Continued)

\begin{tabular}{|c|c|c|c|}
\hline & $\mathrm{n}$ & $\begin{array}{l}\text { Median survival, } \\
\text { days ( } 95 \% \mathrm{Cl})\end{array}$ & $P^{b}$ \\
\hline \multicolumn{4}{|l|}{ PT/INR prolongation } \\
\hline No & 259 & $29(16-51)$ & \multirow[t]{2}{*}{$<0.001$} \\
\hline Yes & 200 & $20(10-34)$ & \\
\hline \multicolumn{4}{|l|}{ C-reactive protein ${ }^{a}$} \\
\hline Low & 239 & $29(14-52)$ & \multirow[t]{2}{*}{0.007} \\
\hline High & 233 & $22(12-38)$ & \\
\hline \multicolumn{4}{|l|}{ Sodium level } \\
\hline Within normal range & 219 & $28(14-49)$ & \multirow[t]{3}{*}{$<0.001$} \\
\hline Hyponatremia & 253 & $25(13-43)$ & \\
\hline Hypernatremia & 15 & $6(3-28)$ & \\
\hline \multicolumn{4}{|l|}{ Potassium level } \\
\hline Within normal range & 394 & $27(14-46)$ & \multirow[t]{3}{*}{0.118} \\
\hline Hypokalemia & 65 & $26(13-43)$ & \\
\hline Hyperkalemia & 28 & $19(10-27)$ & \\
\hline
\end{tabular}

Cl confidence interval, ECOG-PS Eastern Cooperative Oncology Group performance status, PT/INR prothrombin time/international normalized ratio ${ }^{\mathrm{a}}$ Median value applied

bog-rank test

hyponatremia in a variety of cancers $[19,20]$. Yoon et al. also demonstrated a relationship between hyponatremia and shorter survival time in terminally ill cancer patients [21]. However, the results of another study failed to support this relationship in Korean patients with terminal cancer entering a hospice unit, although hampered by a relatively short median survival time (9.5 days) [22]. To our knowledge, the present analysis offers the most fully controlled results in a comparable setting, adjusted for potential confounders. Also, our subjects survived longer than those in previous studies. Even so, hyponatremia was not predictive of poor survival under these conditions. Further prospective studies to explore the prognostic significance of hyponatremia are nevertheless warranted.

At present, evidence of the prognostic value of potassium disorders is sparse. Cui et al. observed an association between serum potassium level and survival time, but significance was not reached in multivariable analysis [23]. In our study, hyperkalemia similarly did not emerge from multivariable analysis as a significant predictor of poor prognosis. One retrospective study conducted in Taiwan cited a serum potassium level $>5$ $\mathrm{mg} / \mathrm{dL}$ as an objective index of short-term survival (7 days) in patients with advanced cancer [11]. However, other researchers found no prognostic significance attached to potassium imbalance $[2,22]$.

There are acknowledged limitations to interpreting our results. First, the cohort is only representative of a single center, and the number of hypernatremic patients 


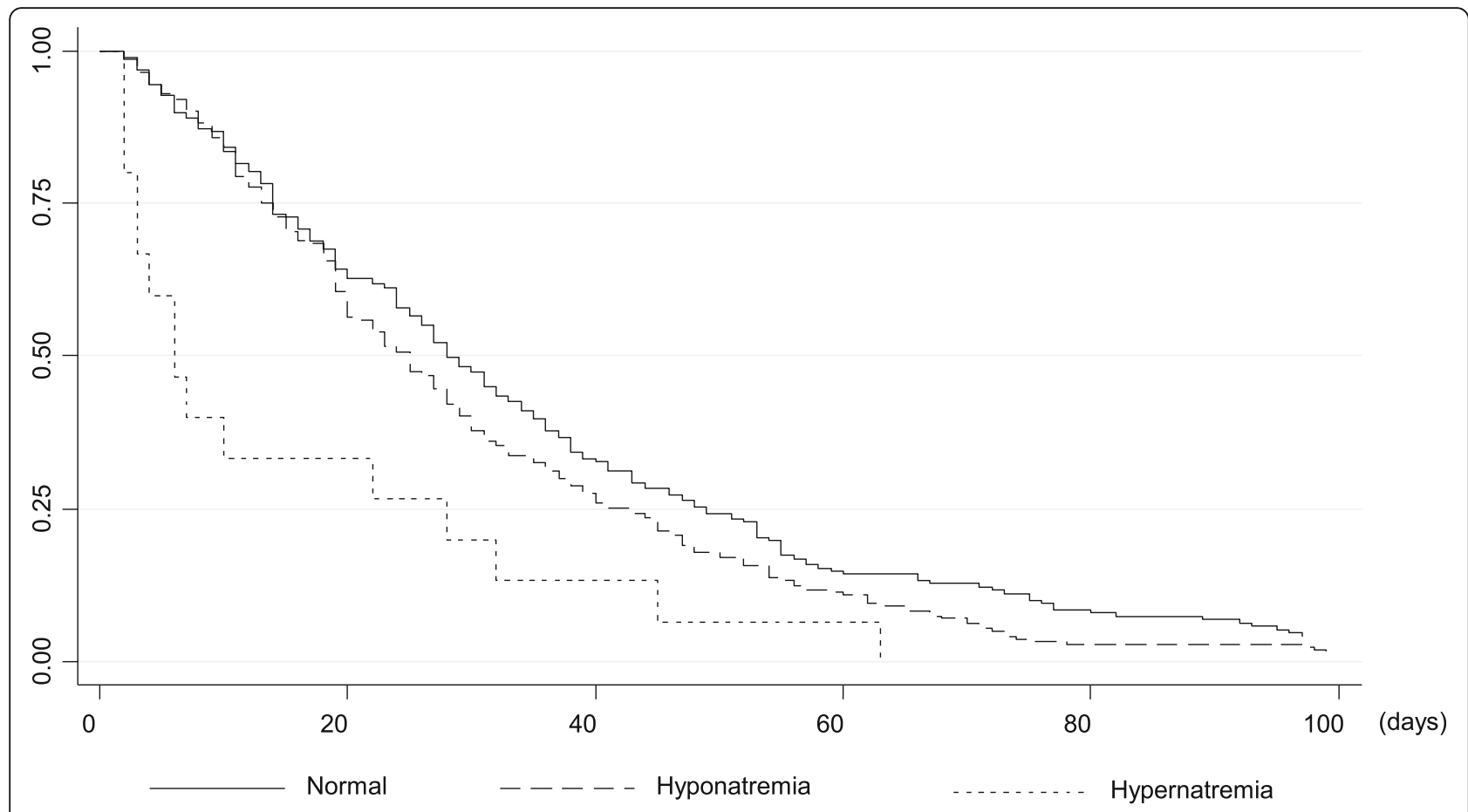

Fig. 1 Kaplan-Meier survival curves of terminal cancer patients plotted by sodium level (note significantly shorter survival in patients with hypernatremia)

Table 3 Independent prognostic indices of survival (Cox proportional hazards model)

\begin{tabular}{|c|c|c|c|c|}
\hline & Univariable anal) & & Multivariable ana & \\
\hline & $\mathrm{HR}(95 \% \mathrm{Cl})$ & $P$-value & $\mathrm{HR}(95 \% \mathrm{Cl})$ & $P$-value \\
\hline Advanced age (> 70 years) & $1.31(1.09-1.58)$ & 0.004 & & \\
\hline Male sex & $1.21(1.01-1.46)$ & 0.038 & $1.53(1.15-2.04)$ & 0.004 \\
\hline Poor functional score $(E C O G=4)$ & $1.30(1.08-1.57)$ & 0.005 & $1.45(1.09-1.94)$ & 0.011 \\
\hline Lung cancer & $1.20(0.96-1.50)$ & 0.108 & & \\
\hline Active infection & $1.06(0.87-1.28)$ & 0.564 & & \\
\hline Leukocytosis & $1.56(1.29-1.87)$ & $<0.001$ & $1.98(1.47-2.66)$ & $<0.001$ \\
\hline Neutrophilia & $1.45(1.19-1.75)$ & $<0.001$ & & \\
\hline Lymphopenia & $1.53(1.20-1.94)$ & 0.001 & & \\
\hline Anemia & $0.95(0.71-1.26)$ & 0.711 & & \\
\hline Thrombocytopenia & $1.28(1.04-1.59)$ & 0.022 & & \\
\hline Azotemia & $1.30(1.06-1.61)$ & 0.013 & & \\
\hline Hypoalbuminemia & $1.88(1.54-2.28)$ & $<0.001$ & $2.06(1.49-2.73)$ & $<0.001$ \\
\hline Hyperbilirubinemia & $1.47(1.21-1.80)$ & $<0.001$ & & \\
\hline PT/INR prolongation & $1.46(1.21-1.77)$ & $<0.001$ & & \\
\hline CRP elevation & $1.28(1.07-1.54)$ & 0.008 & & \\
\hline Hypokalemia & $1.01(0.77-1.32)$ & 0.958 & & \\
\hline Hyperkalemia & $1.22(1.01-1.48)$ & 0.044 & & \\
\hline Hyponatremia & $1.24(1.03-1.49)$ & 0.025 & & \\
\hline Hypernatremia & $1.59(1.22-2.07)$ & 0.001 & $1.55(1.18-2.03)$ & 0.002 \\
\hline
\end{tabular}


was small. Considering the low prevalence of hypernatremia in terminal cancer patients, large-scale multicenter investigations would be helpful to determine the actual prognostic import of hypernatremia under such circumstances. Another drawback is the lack of sequential or interventional data on serum sodium levels. A previous study indicated that hyponatremia normalization is prognostically beneficial in patients with advanced non-small cell lung cancers [24]. One may thus infer that without normalization, patients with persistent hypernatremia will fare worse. Finally, we did not consider potential confounders related with symptoms such as anorexia-cachexia, delirium, dyspnea, and edema.

\section{Conclusion}

Hypernatremia on admission for palliative care of terminal cancer is predictive of shorter patient survival. Despite its low prevalence (3\%), greater clinical attention should be paid to the prognostic utility of hypernatremia.

\section{Abbreviations \\ CRP: C-Reactive Protein; LDH: Lactate DeHydrogenase; INR: International Normalized Ratio; ECOG-PS: Eastern Cooperative Oncology Group Perfomance Status; WBC: White Blood Cell; ADH: AntiDiuretic Hormone}

\section{Acknowledgements}

Not applicable.

\section{Authors' contributions}

All authors have participated sufficiently in this work to take public responsibility for appropriate portions of the content and have read and approved the final manuscript. Specific author contributions were: MSS: analysis of data, interpretation, drafting the manuscript, and final revision. ICH: study design, analysis of data, interpretation, and critical revision of the manuscript. JHJ: study conception, design, interpretation, and revision the statistical session. HHL: study design, acquisition of data, and analysis of data. JHC: study conception, acquisition, interpretation, and drafting sections of the manuscript. JYS: interpretation, critical revision the discussion session.

\section{Funding}

This work was supported by the Gachon University Gil Medical Center (Grant number: FRD2019-11).

\section{Availability of data and materials}

The datasets used and/or analyzed during the current study are available from the corresponding author on reasonable request.

\section{Ethics approval and consent to participate}

The institutional review board of Gachon University Gil Medical Center approved this study (GCIRB2019-149), waiving the need for informed patient consent as designed.

\section{Consent for publication}

Not applicable.

\section{Competing interests}

The authors declare that they have no competing interests.

\section{Author details}

'Department of Family Medicine, Incheon St. Mary's Hospital, 56 Dongsuro, Bupyung-gu, Incheon, Republic of Korea. '2Department of Family Medicine, Yonsei University Graduate School of Medicine, 211 Eonju-ro, Dogok-dong, Gangnam-gu, Seoul, Republic of Korea. ${ }^{3}$ Department of Family Medicine, Gil
Medical Center, Gachon University College of Medicine, 1198 Guwol-dong, Namdong-gu, Incheon 405-760, Republic of Korea. ${ }^{4}$ Artificial Intelligence and Bigdata Convergence Center, Gachon University College of Medicine Guwol-dong, Namdong-gu, Incheon 405-760, Republic of Korea.

Received: 9 December 2019 Accepted: 26 June 2020

Published online: 01 July 2020

\section{References}

1. Hui D. Prognostication of survival in patients with advanced cancer: predicting the unpredictable? Cancer Control. 2015;22:489-97.

2. Reid VL, McDonald R, Nwosu AC, Mason SR, Probert C, Ellershaw JE, et al. A systematically structured review of biomarkers of dying in cancer patients in the last months of life; an exploration of the biology of dying. PLoS One. 2017:12:e0175123.

3. Kawai N, Yuasa N. Laboratory prognostic score for predicting 30-day mortality in terminally ill cancer patients. Nagoya J Med Sci. 2018;80:571-82.

4. Rosner MH, Dalkin AC. Electrolyte disorders associated with cancer. Adv Chronic Kidney Dis. 2014;21:7-17.

5. Alsirafy SA, Al-Shahri MZ, Hassan A, Hidayetullah M, Ghanem H. Pattern of electrolyte abnormalities among cancer patients referred to palliative care: a review of 750 patients. Prog Palliat Care. 2007:15:182-6.

6. Berardi R, Rinaldi S, Caramanti M, Grohè C, Santoni M, Morgese F, et al. Hyponatremia in cancer patients: time for a new approach. Crit Rev Oncol Hematol. 2016;102:15-25.

7. Petereit C, Zaba O, Teber I, Grohe C. Is hyponatremia a prognostic marker of survival for lung cancer? Pneumologie. 2011;65:565-71.

8. Khan MI, Dellinger RP, Waguespack SG. Electrolyte disturbances in critically ill cancer patients: an endocrine perspective. J Intensive Care Med. 2018;33: 147-58.

9. Salahudeen AK, Doshi SM, Shah P. The frequency, cost, and clinical outcomes of hypernatremia in patients hospitalized to a comprehensive cancer center. Support Care Cancer. 2013:21:1871-8.

10. Alsirafy SA, Sroor MY, Al-Shahri MZ. Predictive impact of electrolyte abnormalities on the admission outcome and survival of palliative care cancer referrals. J Palliat Med. 2009;12:177-80.

11. Chen YT, Ho CT, Hsu HS, Huang PT, Lin CY, Liu CS, et al. Objective palliative prognostic score among patients with advanced cancer. J Pain Symptom Manag. 2015:49:690-6.

12. Muhsin SA, Mount DB. Diagnosis and treatment of hypernatremia. Best Pract Res Clin Endocrinol Metab. 2016;30:189-203.

13. Feliu J, Jiménez-Gordo AM, Madero R, Rodríguez-Aizcorbe JR, Espinosa E, Castro J, et al. Development and validation of a prognostic nomogram for terminally ill cancer patients. J Natl Cancer Inst. 2011;103:1613-20.

14. Yun YH, Lee MK, Kim SY, Lee WJ, Jung KH, Do YR, et al. Impact of awareness of terminal illness and use of palliative care or intensive care unit on the survival of terminally ill patients with cancer: prospective cohort study. J Clin Oncol. 2011:29:2474-80.

15. Tsai JS, Wu CH, Chiu TY, Hu WY, Chen CY. Symptom patterns of advanced cancer patients in a palliative care unit. Palliat Med. 2006;20:617-22.

16. Phillips PA, Bretherton M, Johnston Cl, Gray L. Reduced osmotic thirst in healthy elderly men. Am J Phys. 1991;261:R166-71.

17. Lindner G, Funk GC. Hypernatremia in critically ill patients. J Crit Care. 2013; 28:216.e211-20.

18. Stone PC, Lund S. Predicting prognosis in patients with advanced cancer. Ann Oncol. 2007;18:971-6.

19. Yang $Y$, Sun $N$, Sun $P$, Zhang L. Clinical characteristics and prognosis of elderly small cell lung cancer patients complicated with hyponatremia: a retrospective analysis. Anticancer Res. 2017;37:4681-6.

20. Penttila P, Bono P, Peltola K, Donskov F. Hyponatremia associates with poor outcome in metastatic renal cell carcinoma patients treated with everolimus: prognostic impact. Acta Oncol. 2018;57:1580-5.

21. Yoon J, Ahn SH, Lee YJ, Kim CM. Hyponatremia as an independent prognostic factor in patients with terminal cancer. Support Care Cancer. 2015:23:1735-40.

22. Lee GJ, Ahn HS, Go SE, Kim JH, Seo MW, Kang SH, et al. Patient's factors at entering hospice affecting length of survival in a hospice center. Cancer Res Treat. 2015:47:1-8.

23. Cui J, Zhou L, Wee B, Shen F, Ma X, Zhao J. Predicting survival time in noncurative patients with advanced cancer: a prospective study in China. J Palliat Med. 2014;17:545-52. 
24. Berardi R, Santoni M, Newsom-Davis T, Caramanti M, Rinaldi S, Tiberi M, et al. Hyponatremia normalization as an independent prognostic factor in patients with advanced non-small cell lung cancer treated with first-line therapy. Oncotarget. 2017;8:23871-9.

\section{Publisher's Note}

Springer Nature remains neutral with regard to jurisdictional claims in published maps and institutional affiliations.

Ready to submit your research? Choose BMC and benefit from:

- fast, convenient online submission

- thorough peer review by experienced researchers in your field

- rapid publication on acceptance

- support for research data, including large and complex data types

- gold Open Access which fosters wider collaboration and increased citations

- maximum visibility for your research: over $100 \mathrm{M}$ website views per year

At $\mathrm{BMC}$, research is always in progress.

Learn more biomedcentral.com/submissions 